\title{
Endoscopic Therapy and Radiologic Intervention of Acute Gastroesophageal Variceal Bleeding
}

\author{
Jeong Eun Song and Byung Seok Kim \\ Department of Internal Medicine, Daegu Catholic University School of Medicine, Daegu, Korea
}

Acute gastroesophageal variceal hemorrhage is a dreaded complication in patients with liver cirrhosis. Endoscopic therapy and radiologic intervention for gastroesophageal bleeding have rapidly developed in the recent decades. Endoscopic treatment is initially performed to stop variceal hemorrhage. For the treatment of esophageal variceal bleeding, endoscopic variceal ligation (EVL) is considered the endoscopic treatment of choice. In cases of gastric variceal hemorrhage, the type of gastric varices (GVs) is important in deciding the strategy of endoscopic treatment. Endoscopic variceal obturation (EVO) is recommended for fundal variceal bleeding. For the management of gastroesophageal varix type 1 bleeding, both EVO and EVL are available treatment options; however, EVO is preferred over EVL. If endoscopic management fails to control variceal hemorrhage, radiologic interventional modalities could be considered. Transjugular intrahepatic portosystemic shunt is a good option for rescue treatment in refractory variceal bleeding. In cases of refractory hemorrhage of GVs in patients with a gastrorenal shunt, balloon-occluded retrograde transvenous obliteration could be considered as a salvage treatment. Clin Endosc 2019;52:407-415

Key Words: Esophageal and gastric varices; Hemorrhage; Endoscopy; Radiology; Interventional

\section{INTRODUCTION}

In cirrhotic patients, the most common complication is portal hypertension, defined as a pathologic increase in portal venous pressure. Portal hypertension occurs with increased resistance to portal flow in association with increased portal venous blood flow caused by splanchnic vasodilatation. ${ }^{1}$ In this condition, collaterals are usually generated to reduce the increased portal pressure and blood flow. Gastroesophageal varices (GOVs) are the most significant collaterals, and they could grow and finally rupture with the aggravation of portal hypertension. ${ }^{2}$

Acute hemorrhage from GOVs is one of the most lethal

Received: September 11, 2019 Revised: September 19, 2019

Accepted: September 19, 2019

Correspondence: Byung Seok Kim

Department of Internal Medicine, Daegu Catholic University School of Medicine, 33 Duryugongwon-ro 17-gil, Nam-gu, Daegu 42472, Korea

Tel: +82-53-650-4090, Fax: +82-53-656-3281, E-mail: kbs9225@cu.ac.kr

ORCID: https://orcid.org/0000-0002-4318-4570

(c) This is an Open Access article distributed under the terms of the Creative Commons Attribution Non-Commercial License (http://creativecommons.org/ licenses/by-nc/3.0) which permits unrestricted non-commercial use, distribution, and reproduction in any medium, provided the original work is properly cited. complications of portal hypertension and a leading cause of mortality in cirrhotic patients. ${ }^{3}$ Thus, the initial management of acute variceal bleeding is crucial, which is broadly divided into the following categories: (1) general management including resuscitation, vasoactive agents, and prophylactic antibiotics and (2) therapeutic endoscopy. General management is well defined in the recent guidelines. ${ }^{4,5}$ Patients with acute variceal bleeding should be treated in the intensive care unit to maintain the circulatory and respiratory status. For restoring hemodynamic stability, packed red blood cell transfusion should be initiated, with a target hemoglobin level of 7-9 g/dL. For reducing portal pressure, intravenous infusion of vasoactive drugs, including somatostatin, terlipressin and octreotide, should be administered in combination with therapeutic endoscopy, with the infusion continued for 3-5 days. Bacterial infection frequently occurs in cirrhotic patients with upper gastrointestinal (GI) bleeding and is related to high mortality rates. Recent guidelines recommend antibiotic prophylaxis in all cirrhotic patients with acute variceal bleeding. The best antibiotic choice is intravenous $1 \mathrm{~g}$ ceftriaxone every $24 \mathrm{~h}$ for a maximum of 7 days.

In the last three decades, bleeding-related mortality has 
decreased from about $50 \%$ to $15 \%-20 \%$ owing to the standardization of supportive care and advances in endoscopic treatment and radiologic intervention. ${ }^{5}$ This review focuses on the currently available endoscopic therapy and radiologic intervention for acute GOV bleeding based on recent studies.

\section{TIMING OF ENDOSCOPY FOR VARICEAL BLEEDING}

It is generally accepted that upper GI endoscopy should be conducted to identify variceal hemorrhage in cirrhotic patients with hematemesis. ${ }^{6}$ However, the optimal timing of endoscopy remains undetermined. One retrospective study showed that bleeding-related mortality was not associated with the timing of endoscopy in hemodynamically stable condition. ${ }^{7}$ In contrast, two studies reported that the mortality rate was lower in patients with early endoscopic treatment than in those with delayed endoscopic treatment. ${ }^{8,9}$ Although the optimal timing of endoscopy could not be confirmed, recent guidelines recommend that endoscopy should be conducted within $12 \mathrm{~h}$ in cirrhotic patients with acute upper GI bleeding.

\section{MANAGEMENT OF ESOPHAGEAL VARICEAL BLEEDING}

\section{Esophageal varices}

About $30 \%-40 \%$ of cirrhotic patients with compensated liver function have esophageal varices (EVs), while approximately $85 \%$ of patients with decompensated cirrhosis have EVs. The 1-year rate of a first variceal bleeding is about $10 \%-15 \%$. About $60 \%$ of patients experience recurrent variceal bleeding within 1 year in the absence of proper treatment. ${ }^{5}$

In the thoracic esophagus, venous drainage to systemic veins mainly occurs through the azygos and hemiazygos venous system. In contrast, the abdominal esophagus predominantly drains into the portal venous system through the left gastric vein and partly to the inferior vena cava through the superior and inferior phrenic veins. With reversal flow in portal hypertension, the left gastric vein generally acts as the afferent vessel providing blood to EVs in patients with cirrhosis.

\section{Endoscopic management}

The endoscopic diagnosis of esophageal variceal hemorrhage depends on the presence of varices with a white nipple sign (Fig. 1A) or active bleeding (Fig. 1B). The blood in the stomach and large varices with red wale marks (Fig. 1C) in the absence of other potential sources of bleeding are also considered evidence of esophageal variceal hemorrhage..$^{10}$ Endoscopy should be conducted as soon as possible, preferably within 12 hours, in cirrhotic patients with hematemesis. If variceal bleeding is suspected, endoscopic therapy should be performed. The aim of endoscopic therapy for EV is to decrease variceal wall tension through variceal obliteration. The endoscopic modalities for treating esophageal variceal hemorrhage are endoscopic injection sclerotherapy (EIS) and endoscopic variceal ligation (EVL).

EIS involves the injection of a sclerosing agent including sodium tetradecyl sulfate, ethanolamine oleate, or absolute alcohol into the variceal lumen or adjacent to the varices. Injected sclerosing agents cause injury to endothelial cells, destruct the red blood cells, and result in thrombosis of varices. ${ }^{11}$ For complete obliteration of the varices, repeated sessions should be performed. Before EVL, EIS was the first-line treatment for esophageal variceal bleeding, as it was proven to be superior to balloon tamponade or vasoconstrictor administration in terms of bleeding control. However, EIS is no longer considered as standard treatment because it has a higher rate of treatment failure and more complications than EVL. ${ }^{12,13}$

Currently, EVL is considered the gold standard therapy for esophageal variceal bleeding. ${ }^{6}$ Contrary to EIS that involves
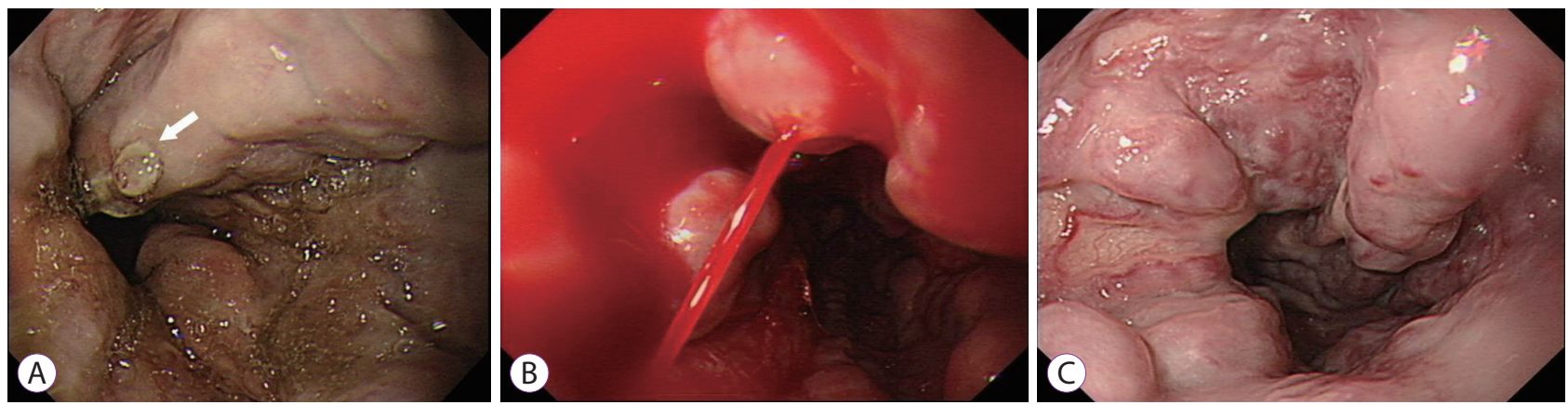

Fig. 1. Endoscopic diagnosis of esophageal variceal bleeding. (A) Large esophageal varix (EV) with a white nipple sign (arrow). (B) Active bleeding due to rupture of the esophageal varix. (C) Large EV with red wale marks. 
chemical obliteration, EVL eradicates varices through mechanical strangulation with rubber bands. In EVL, variceal columns are sucked into a transparent cap mounted on the tip of the endoscope and ligated with rubber bands. Multiband devices are more commonly employed than the original single-band ligators because multiband devices are much simpler and quicker to use and do not need an overtube. ${ }^{14}$ Once the varix is identified, the tip of the endoscope is pointed toward the varix, which is then continuously sucked into the transparent cap. During the suctioning of the varix into the cap, the rubber band can be fired when a "red-out" sign appears (Fig. 2A, B). ${ }^{15}$ Generally, the procedure is conducted by starting the deployment of the bands at the gastroesophageal junction and working upwards in a spiral pattern to prevent overlapping circumferential deployment of bands at the same level..$^{11}$ It is better to place at least one band on each distinct variceal column. In the presence of active bleeding, the field of vision might be restricted by the cap mounted on the tip of endoscope. Water infusion and suction can help in visualizing the bleeding focus. If possible, the rubber band should be de- ployed at the site of variceal bleeding. However, if the bleeding point cannot be confirmed, blind multiband ligations at the gastroesophageal junction may sufficiently reduce hemorrhage to obtain a field of vision and subsequently performing proper ligation. ${ }^{15,16}$ Currently, the Baveno VI guidelines recommend that patients presenting with acute variceal bleeding should be treated with a combination therapy of EVL and vasoactive drugs. ${ }^{6}$

\section{Management of patients with endoscopic hemosta- sis failure}

As failure to control bleeding leads to death, it indicates the necessity to change the treatment option. Hemostasis failure is defined by one of the following criteria occurs within 5 days of an acute bleeding episode: (1) $\geq 100 \mathrm{~mL}$ fresh hematemesis for $2 \mathrm{~h}$ after the initiation of therapeutic endoscopy, (2) occurrence of hypovolemic shock, and (3) $3 \mathrm{~g} / \mathrm{dL}$ decrease in hemoglobin within any $24 \mathrm{~h}$ period without transfusion. ${ }^{4}$

In patients with standard treatment failure, the transjugular intrahepatic portosystemic shunt (TIPS) is considered the best
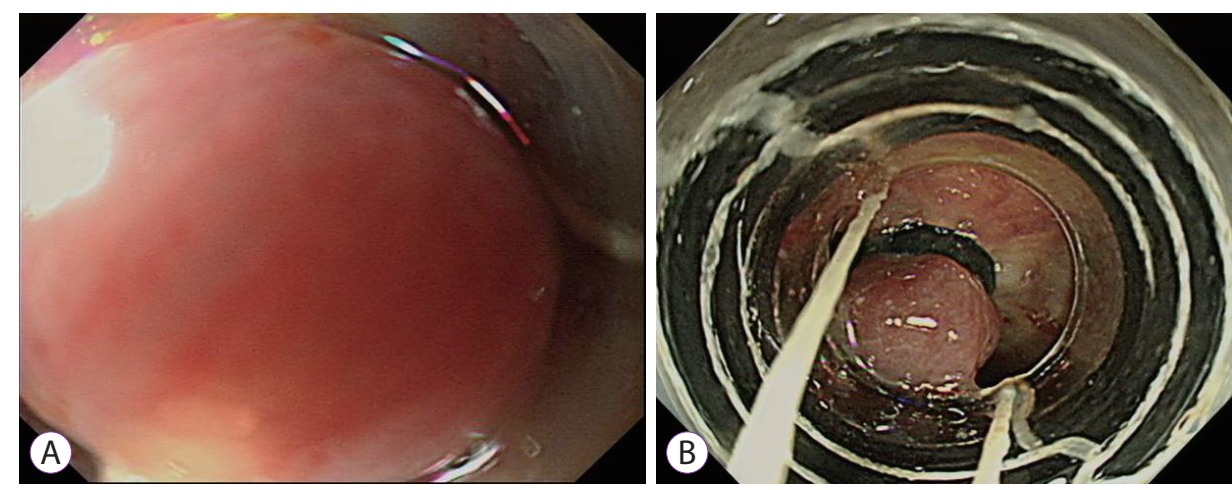

Fig. 2. Endoscopic variceal ligation. (A) The "red-out" sign appears when the varix is fully sucked into the cap. (B) Successfully deployed band ligation on the varix.
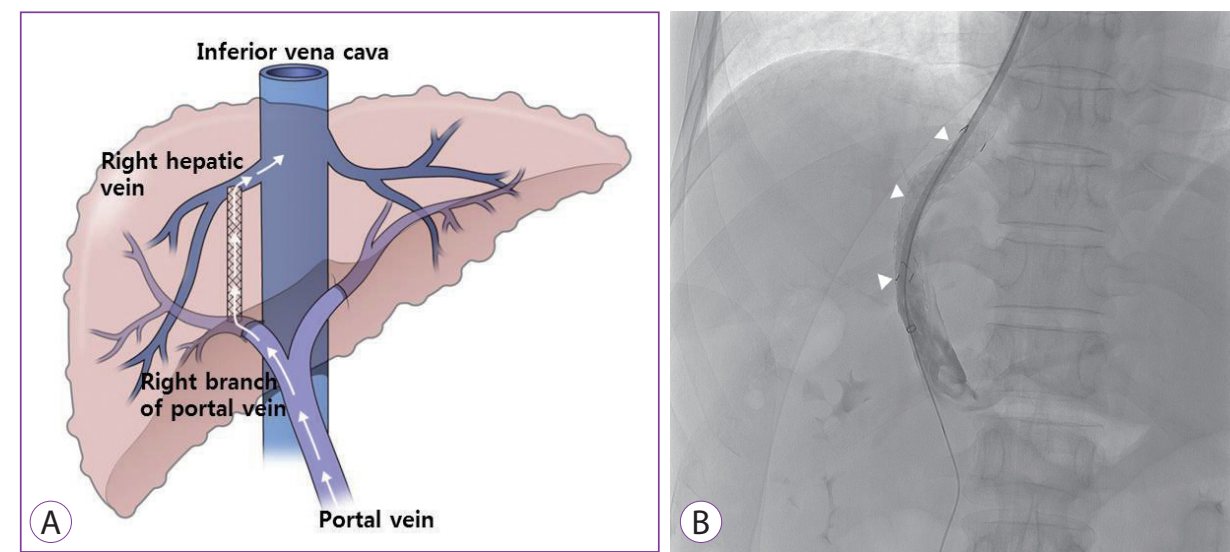

Fig. 3. Transjugular intrahepatic portosystemic shunt (TIPS). (A) TIPS is a radiologic interventional technique that involves inserting a stent to connect the portal vein to the hepatic vein. It relieves portal hypertension, allowing the blood to flow directly from the portal vein to the systemic venous system. (B) Fluoroscopic image of TIPS. The portal venogram obtained after TIPS shows flow through the stent (arrowheads). 
rescue treatment. ${ }^{17}$ This procedure is performed to establish a low-resistance tract between the hepatic vein and the portal vein through an angiographic technique (Fig. 3A, B). The patency of the tract is maintained by placing an expandable metal stent, thereby permitting blood to flow directly from the portal vein to the systemic circulation. TIPS controls variceal hemorrhage by decompressing the portal pressure. In a prospective study conducted in 58 patients as soon as possible after the diagnosis of refractory variceal hemorrhage, the efficacy of salvage TIPS was higher than that of EIS combined with vasoactive drugs. After salvage TIPS, variceal bleeding was controlled in 52 of 58 patients (90\%), and the survival rate was $51.7 \%$ and $40.2 \%$ at 1 year and 3 years, respectively. ${ }^{17}$ The major cause of variceal rebleeding after TIPS is obliteration or stenosis of the stent. Since the introduction of polytetrafluoroethylene-covered stents, markedly improved longterm stent patency compared with bare metal stents has been achieved. $^{18,19}$

Balloon tamponade, which uses a nasogastric tube with two inflatable balloons attached (for the esophagus and stomach), showed high hemostasis efficacy in patients with acute esophageal variceal hemorrhage, whereas $\geq 50 \%$ of patients experienced rebleeding after deflation. ${ }^{20}$ In addition, because it is related to serious adverse events such as aspiration pneumonia, as well as ulceration or perforation of the esophagus, the deployed balloon should not be retained for $>24 \mathrm{~h}$. Thus, balloon tamponade should only be considered in massive hemorrhage as a short-term bridging therapy before a more definite treatment such as TIPS. ${ }^{4}$

\section{MANAGEMENT OF GASTRIC VARICEAL BLEEDING}

\section{Gastric varices}

Compared with EVs, gastric varices (GVs) have lower incidence and bleeding rate. ${ }^{21}$ However, gastric variceal bleeding is usually more massive, requires more transfusions, and is related to higher rebleeding and mortality rates than esophageal variceal bleeding. ${ }^{3,21,22}$

The Sarin classification system is the most widely used and practical method for risk stratification and treatment of GVs (Fig. 4). ${ }^{21}$ GVs are categorized into GOVs and isolated GVs (IGVs) based on the association of GVs with EVs. According to their location in the stomach, GOVs and IGVs are both subclassified into type 1 and type 2. GOVs are a continuation of EVs spreading out either into the lesser curvature (GOV1s) or the fundus along the greater curvature (GOV2s). IGV1s are situated in the fundus of the stomach and IGV2s are isolated ectopic varices that are present at any location in the stomach except the fundus or the intestine. Hemodynamically, EVs and GOV1s arise from the left and right gastric veins, whereas IGV1s and GOV2s are usually supplied by the short and posterior gastric veins. ${ }^{23}$ IGV2s are supplied by the gastroepiploic veins. ${ }^{24}$ The risk of bleeding is significantly higher in fundal varices than in either GOV1s or IGV2s. ${ }^{21}$

\section{Endoscopic treatment for GOV2 and IGV1 bleeding}

GOV2s and IGV1s are collectively called fundal varices and supplied by the short and posterior gastric veins. ${ }^{23}$ Fundal variceal bleeding commonly occurs in large varices and is accompanied by a gastrorenal or splenorenal shunt. ${ }^{25}$ Because fundal varices have a large volume and fast flow of blood, bleeding control is difficult and the rebleeding rate is high.

Endoscopic variceal obturation (EVO) is the therapeutic endoscopy method of choice for acute bleeding from GOV2s and IGV1s. ${ }^{4,26,27}$ GVs are obturated by injecting a tissue adhesive agent, such as cyanoacrylate, which leads to solidification and thrombosis in the varices. ${ }^{24}$ Contrary to sclerosing agents used in EIS, which induce thrombosis and fibrosis of varices through endothelial damage, cyanoacrylate is rapidly transformed into a hard plastic material within varices, resulting in their solidification and thrombosis. The standard protocol uses a mixture of cyanoacrylate and Lipiodol in a 1:1 ratio to delay premature hardening. The mixture of cyanoacrylate and Lipiodol is directly injected into the GVs at $1-2 \mathrm{~mL}$ each time with a needle catheter. Immediately after injection, distilled water should be passed to deliver the cyanoacrylate from the dead space of the catheter lumen to GVs. Before the procedure, the dead space of catheter lumen should be checked to
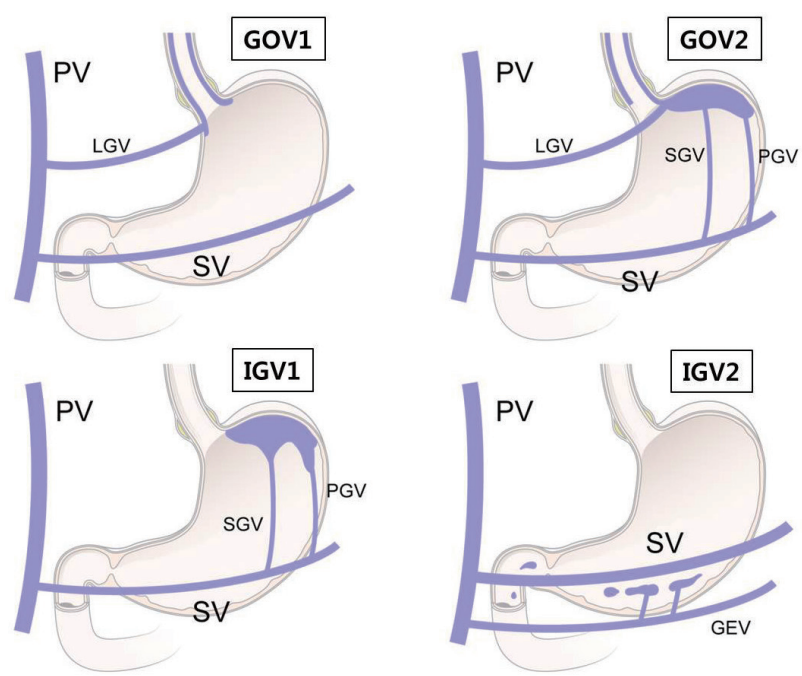

Fig. 4. Sarin classification of gastric varices. GEV, gastric epiploic vein; GOV, gastroesophageal varix; IGV, isolated gastric varix; LGV, left gastric vein; PGV, posterior gastric vein; $P V$, portal vein; SGV, short gastric vein; SV, splenic vein. 
confirm the volume of distilled water for flushing. The needle should be promptly extracted after cyanoacrylate injection to prevent it from being embedded in the varix. After extracting the needle, distilled water should be passed into the catheter lumen at high speed for 15-20 s to prevent closure of the catheter lumen. Until the varix is hard enough to touch with a needle catheter, repeated injection could be performed. ${ }^{28}$ When deciding the site of injection, the direction of variceal blood flow and the variceal size should be considered. Huge fundal varices have a large volume and rapid flow of blood from the cardia to the fundus. Theoretically, the dome of the varix has the highest pressure and fastest blood flow. Thus, the most protruding portion or the nipple sign of the varix should be avoided to prevent massive bleeding. Therefore, it is safer to inject at the branch of the cardia area, which has lower pressure (Fig. 5). ${ }^{29}$ After EVO therapy, cyanoacrylate gradually causes an inflammatory response and eliminates vascular endothelial cells, causing variceal obliteration. The complications that could occur after EVO are fever, infection, perforation, gastric ulcer, and peritonitis. ${ }^{28}$ Severe complications are mostly associated with distant embolic events such as pulmonary, cerebral, and splenic infarction. ${ }^{30}$ In several studies evaluating the efficacy of EVO for acute gastric variceal bleeding, the success rate of hemostasis was $91 \%-97 \%$ and the rebleeding rate was $17 \%-49 \%$ at 1 year. ${ }^{31-33} \mathrm{~A}$ recent meta-analysis reported that EVO achieved a significantly higher hemostasis success rate (odds ratio [OR], 4.44; 95\% confidence interval $[\mathrm{CI}], 1.14-17.3)$ and a lower rebleeding rate $(\mathrm{OR}, 0.06 ; 95 \% \mathrm{CI}$, 0.01-0.58) than EVL. ${ }^{34}$

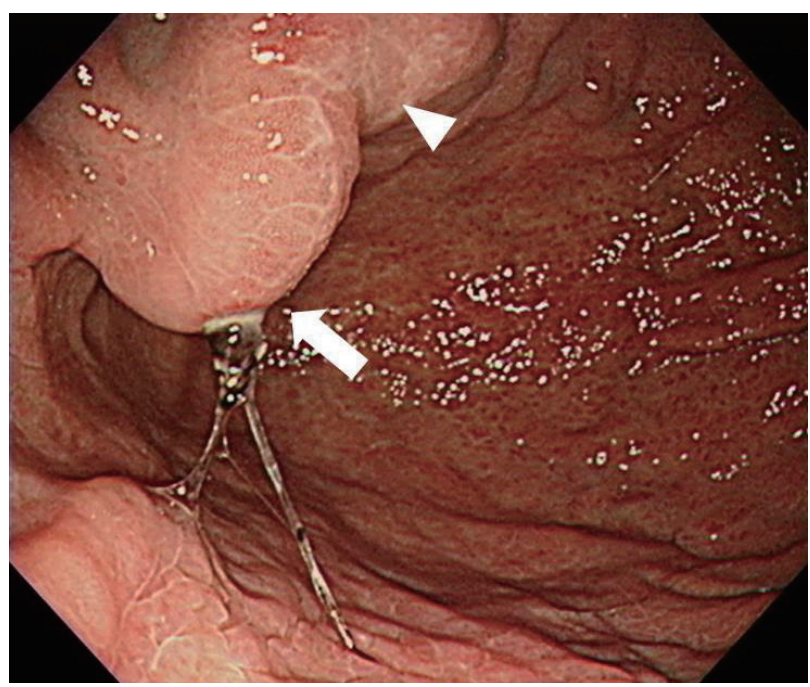

Fig. 5. Strategic approach for endoscopic variceal obturation of fundal varices. The top of the variceal dome (arrow) has high intravariceal pressure, which can cause immediate spurting of injected cyanoacrylate and massive hemorrhage. Thus, it is better to first inject cyanoacrylate at the side of the varix (arrowhead) where there is lower pressure.

\section{Endoscopic treatment for GOV1 bleeding}

GOV1s are more similar to EVs than GOV2s and IGV1s in terms of size and route of portal blood flow, including having a smaller size than fundal varices as well as afferent venous drainage through the left and right gastric veins. GOV1s are closely connected with EVs because obliteration of EVs with EVL or EIS frequently induces resolution of GVs in 60\%-65\% of patients with GOV1s. ${ }^{21,35}$ Therefore, GOV1s are usually treated with EVL, similar to EVs. However, GOV1s are present in the stomach where the overlying mucosal layer is thicker than that in the esophagus. The thick overlying mucosal layer of GVs could result in incomplete ligation of varices with EVL, which could induce massive hemorrhage after detaching the rubber band from the stomach mucosa. ${ }^{36,37}$ Furthermore, bleeding from post-EVL ulcers could occur more frequently in the stomach than in the esophagus. ${ }^{38}$ In fact, EVO seems to be superior to EVL in treating acute bleeding from GOV1s. In several randomized controlled trials and retrospective studies, the success rate of hemostasis was $85 \%-100 \%$ with EVO and $80 \%-90 \%$ with EVL, and the rebleeding rate was 3\%-26\% with EVO and 14\%-56\% with EVL. ${ }^{35,38-40}$ In addition, a recent meta-analysis showed that the efficacy of EVO was superior to that of EVL in preventing rebleeding from GOV1s (OR, $0.39 \%$; $95 \%$ CI, $0.16-0.94 ; p=0.035) .{ }^{34}$ In summary, both EVO and EVL are available treatment options; however, EVO is preferred over EVL.

\section{Radiologic intervention for the management of acute and refractory gastric variceal bleeding}

From the point of view of interventional radiologists, the main modalities available for the treatment of GVs are TIPS and balloon-occluded retrograde transvenous obliteration (BRTO).

TIPS induces hemostasis of gastric variceal bleeding and decreases the risk of rebleeding by decompressing the portal pressure. In two retrospective studies comparing TIPS and EVO in patients with fundal variceal bleeding, the hemostasis rate was $\geq 90 \%$ with both TIPS and EVO; however, TIPS had more adverse effects such as hepatic encephalopathy and stent stenosis, and was more expensive than EVO. ${ }^{41,42}$ Therefore, TIPS could be an optimal choice in patients with gastric variceal hemorrhage refractory to medical and endoscopic treatment. In several studies assessing the efficacy of salvage TIPS for refractory gastric variceal hemorrhage, the hemostasis rate was $90 \%-100 \%$ and the rebleeding rate was $16 \%-40 \%{ }^{43-46}$

BRTO is a radiologic technique that involves thrombotic obliteration of GVs by instillation of a sclerosing agent into the GV via the gastrorenal or gastrocaval shunt while an inflated balloon occludes the blood flow of the varix (Fig. 6A). Before the procedure, the presence of a spontaneous gas- 
trorenal or gastrocaval shunt should be confirmed with contrast-enhanced computed tomography of the abdomen. Patients with GVs usually have these shunts ${ }^{23}$; however, about $15 \%$ of patients with GVs have other portosystemic shunts and BRTO is not available in these patients. In two retrospective studies assessing the efficacy of BRTO for the management of gastric variceal hemorrhage, the success rate of BRTO was $95 \%-97 \%$, although $20 \%-41 \%$ of patients showed adverse events causing the worsening or relapse of EVs after BRTO. ${ }^{47,48}$ Thus, follow-up endoscopy is needed after BRTO. A recent meta-analysis reported that the technical success rate of BRTO was $96.4 \%$ and the clinical success (defined as no recurrence or rebleeding, or complete obliteration of GVs) rate was $97.3 \%{ }^{49}$ For the treatment of patients with refractory gastric variceal hemorrhage, the efficacy of BRTO is comparable to that of TIPS. ${ }^{50}$ Currently, a modification of BRTO, plug-assisted retrograde transvenous obliteration (PARTO), has been introduced to reduce the complications of BRTO related to the use of a sclerosing agent and a balloon catheter (Fig. 6B). In PARTO, a vascular plug and gelatin sponge are used instead of a balloon occlusion catheter and a sclerosing agent. In a recent multicenter prospective study evaluating the efficacy of PARTO in the treatment of GVs, $98.6 \%$ of patients showed complete thrombosis of GVs and gastrorenal shunts within 1 week after PARTO. ${ }^{51}$ Procedure-related adverse events, rebleeding of GVs or hepatic encephalopathy were not reported in the follow-up period. For the management of gastric variceal bleeding, PARTO has the potential to replace BRTO.

In summary, TIPS is recommended as a rescue therapy in patients with refractory gastric variceal bleeding. BRTO could be considered as a salvage treatment in patients with refractory hemorrhage of GVs in the case of having a gastrorenal shunt. In the management of fundal variceal bleeding, TIPS and retrograde transvenous obliteration methods such as BRTO or PARTO could be considered as initial hemostatic therapy.

\section{NEW ENDOSCOPIC MODALITIES IN THE TREATMENT OF VARICEAL BLEEDING}

\section{Hemostatic powder}

Recently, hemostatic powders have been introduced as endoscopic tools for the management of GI bleeding. Hemostatic powder forms a mechanical barrier when it comes into contact with water in the GI tract. Although this technique needs a dedicated delivery system, it requires minimal experience in therapeutic endoscopy. A recent randomized controlled trial evaluated the efficacy of a hemostatic powder for the treatment of acute variceal hemorrhage. ${ }^{52}$ In this study, 86 patients with acute variceal hemorrhage were randomized to receive medical and endoscopic therapy within $12-24$ h of hospital visit or medical treatment and hemostatic powder application within $2 \mathrm{~h}$ of hospital visit followed by endoscopic therapy (EVL for esophageal variceal bleeding, EVO for gastric variceal bleeding) within 12-24 h. Patients who underwent medical therapy and early hemostatic powder application followed by endoscopic therapy showed significantly reduced clinical rebleeding within $24 \mathrm{~h}$ and increased survival rate compared with those who underwent standard medical and endoscopic therapy. This study suggests the role for hemostatic powders
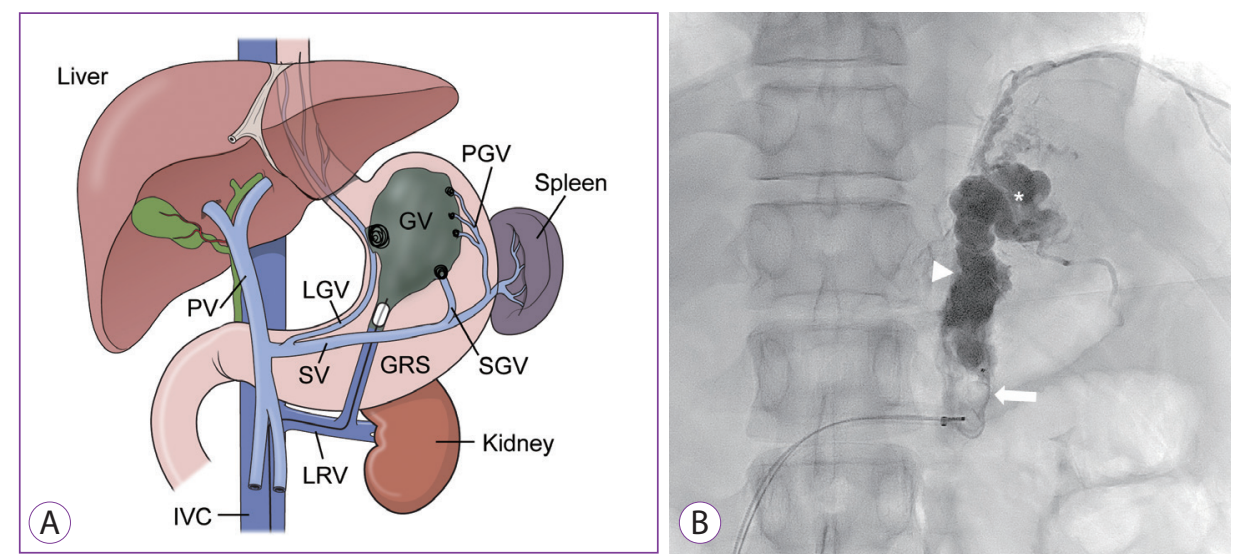

Fig. 6. Retrograde transvenous obliteration. (A) Illustration of balloon-occluded retrograde transvenous obliteration of gastric varices. A balloon catheter is introduced through the femoral vein. Thereafter, the catheter is inserted into the gastrorenal shunt (GRS) via the left renal vein. The balloon is inflated to occlude the shunt, and a sclerosing agent is subsequently injected into the gastric varices for obliteration. (B) Fluoroscopic image of plug-assisted retrograde transvenous obliteration. Gelatin slurry is injected into the gastric varices (asterisk) and GRS (arrowhead) after deploying the vascular plug (arrow) at the GRS. GV, gastric varix; IVC, inferior vena cava; LGV, left gastric vein; LRV, left renal vein; PGV, posterior gastric vein; PV, portal vein; SGV, short gastric vein; SV, splenic vein. 
as an initial therapy for acute variceal bleeding, especially for endoscopists with in minimal expertise.

\section{Self-expandable metallic stents}

Balloon tamponade is effective in controlling refractory esophageal variceal hemorrhage in up to $90 \%$ of cases, while the rebleeding rate is $\geq 50 \%$ after deflation. ${ }^{20}$ In addition, as balloon tamponade is related to serious complications such as ulceration or perforation of the esophagus, as well as aspiration pneumonia, the balloon should not be retained for $\geq 24 \mathrm{~h}$. Self-expandable metallic stents (SEMSs) may provide a useful alternative to esophageal balloon tamponade in patients with refractory acute variceal hemorrhage. In a small-sized randomized controlled trial comparing SEMS with balloon tamponade in patients with refractory esophageal variceal hemorrhage, SEMS showed a higher hemostasis rate (85\% vs. $47 \%, p=0.037)$ and fewer serious adverse events ( $15 \%$ vs. $47 \%$, $p=0.077)$ than balloon tamponade, although the six-week survival rate was not significantly different between the two treatments. ${ }^{53}$ SEMS can be placed and removed endoscopically without fluoroscopy, and can be left in place for up to 2 weeks. This technique could be considered as a bridge therapy to TIPS.

\section{Endoscopic ultrasonography-guided cyanoacrylate and coil embolization}

Endoscopic ultrasonography (EUS)-guided vascular embolization has been introduced as a new option for controlling bleeding. In the endoscopic treatment of GVs, EUS has several strengths. Because it provides real-time, high-quality images of the GI wall and vascular structure, EUS is superior to direct endoscopy in detecting GVs. ${ }^{54}$ Especially during active bleeding, EUS visualization is not restricted. Thus, the detection rate of GVs is higher and a fast therapeutic procedure is possible. After embolization, EUS can confirm the obliteration of vascular flow in the varix through Doppler assessment. These strengths might allow EUS-guided therapy combined with cyanoacrylate and coil in patients with gastric variceal bleeding. This procedure consists of the following three steps: (1) EUS-guided puncture of GVs with a fine-needle aspiration (FNA) needle, (2) coil delivery into the varix through the FNA needle, (3) injection of cyanoacrylate via the FNA needle. ${ }^{55}$ In this procedure, coil might improve hemostasis with a lower dose of cyanoacrylate and decrease the risk of systemic embolization by acting as a layer for retaining cyanoacrylate. A recent study assessed the efficacy of EUS-guided therapy combined with cyanoacrylate and coil in 152 patients with GVs. ${ }^{56}$ The technical success rate was $99 \%$, with a mean coil number of 1.4 and a mean cyanoacrylate volume of $2 \mathrm{~mL}$. In follow-up EUS, 93\% of patients showed complete obliteration of GVs (on Doppler study). The rate of systemic embolization was lower in this study $(0.7 \%)$ than in a previous study with EUS-guided cyanoacrylate injection alone (10.5\%). Although this procedure shows promising results, further studies are needed before it can be considered a treatment option for gastric variceal bleeding.

\section{CONCLUSIONS}

The treatment of acute variceal bleeding requires a multidisciplinary approach involving medical treatment, endoscopic treatment, and radiologic intervention. For hemostasis against initial and recurrent hemorrhage, therapeutic endoscopy is an important modality. The two main methods of endoscopic hemostasis are EVL and EVO, and the choice between these methods is decided according to the type of varices. In case of endoscopic hemostasis failure, radiologic interventions such as TIPS and BRTO are considered good options for salvage therapy. New endoscopic modalities, including hemostatic powders, SEMS, and EUS-guided therapy might find their position in the treatment of acute variceal bleeding through the future studies.

Conflicts of Interest

The authors have no financial conflicts of interest.

ORCID

Jeong Eun Song: https://orcid.org/0000-0002-1034-4478

\section{REFERENCES}

1. García-Pagán JC, Gracia-Sancho J, Bosch J. Functional aspects on the pathophysiology of portal hypertension in cirrhosis. J Hepatol 2012;57:458-461.

2. Garcia-Tsao G, Bosch J. Management of varices and variceal hemorrhage in cirrhosis. N Engl J Med 2010;362:823-832.

3. de Franchis R, Primignani M. Natural history of portal hypertension in patients with cirrhosis. Clin Liver Dis 2001;5:645-663.

4. de Franchis R. Revising consensus in portal hypertension: report of the Baveno $\mathrm{V}$ consensus workshop on methodology of diagnosis and therapy in portal hypertension. J Hepatol 2010;53:762-768.

5. Garcia-Tsao G, Abraldes JG, Berzigotti A, Bosch J. Portal hypertensive bleeding in cirrhosis: risk stratification, diagnosis, and management: 2016 practice guidance by the American Association for the study of liver diseases. Hepatology 2017;65:310-335.

6. de Franchis R. Expanding consensus in portal hypertension: report of the Baveno VI consensus workshop: stratifying risk and individualizing care for portal hypertension. J Hepatol 2015;63:743-752.

7. Cheung J, Soo I, Bastiampillai R, Zhu Q, Ma M. Urgent vs. non-urgent endoscopy in stable acute variceal bleeding. Am J Gastroenterol 2009;104:1125-1129.

8. Hsu YC, Chung CS, Tseng CH, et al. Delayed endoscopy as a risk factor for in-hospital mortality in cirrhotic patients with acute variceal hemor- 
rhage. J Gastroenterol Hepatol 2009;24:1294-1299.

9. Chen PH, Chen WC, Hou MC, et al. Delayed endoscopy increases re-bleeding and mortality in patients with hematemesis and active esophageal variceal bleeding: a cohort study. J Hepatol 2012;57:12071213.

10. Garcia-Tsao G, Sanyal AJ, Grace ND, Carey W. Prevention and management of gastroesophageal varices and variceal hemorrhage in cirrhosis. Hepatology 2007;46:922-938.

11. de Franchis R, Primignani M. Endoscopic treatments for portal hypertension. Semin Liver Dis 1999;19:439-455.

12. Hashizume M, Ohta M, Ueno K, Tanoue K, Kitano S, Sugimachi K. Endoscopic ligation of esophageal varices compared with injection sclerotherapy: a prospective randomized trial. Gastrointest Endosc 1993;39:123-126.

13. Lo GH, Lai KH, Cheng JS, et al. A prospective, randomized trial of sclerotherapy versus ligation in the management of bleeding esophageal varices. Hepatology 1995;22:466-471.

14. Poza Cordon J, Froilan Torres C, Burgos García A, Gea Rodriguez F, Suárez de Parga JM. Endoscopic management of esophageal varices. World J Gastrointest Endosc 2012;4:312-322.

15. Cárdenas A. Management of acute variceal bleeding: emphasis on endoscopic therapy. Clin Liver Dis 2010;14:251-262.

16. Soehendra N, Binmoeller KF. Is sclerotherapy out? Endoscopy 1997;29:283-284

17. Azoulay D, Castaing D, Majno P, et al. Salvage transjugular intrahepatic portosystemic shunt for uncontrolled variceal bleeding in patients with decompensated cirrhosis. J Hepatol 2001;35:590-597.

18. Bureau C, Garcia Pagan JC, Layrargues GP, et al. Patency of stents covered with polytetrafluoroethylene in patients treated by transjugular intrahepatic portosystemic shunts: long-term results of a randomized multicentre study. Liver Int 2007;27:742-747.

19. Yang Z, Han G, Wu Q, et al. Patency and clinical outcomes of transjugular intrahepatic portosystemic shunt with polytetrafluoroethylene-covered stents versus bare stents: a meta-analysis. J Gastroenterol Hepatol 2010;25:1718-1725.

20. Panés J, Terés J, Bosch J, Rodés J. Efficacy of balloon tamponade in treatment of bleeding gastric and esophageal varices. Results in 151 consecutive episodes. Dig Dis Sci 1988;33:454-459.

21. Sarin SK, Lahoti D, Saxena SP, Murthy NS, Makwana UK. Prevalence, classification and natural history of gastric varices: a longterm follow-up study in 568 portal hypertension patients. Hepatology 1992;16:1343-1349.

22. Sarin SK. Long-term follow-up of gastric variceal sclerotherapy: an eleven-year experience. Gastrointest Endosc 1997;46:8-14.

23. Watanabe K, Kimura K, Matsutani S, Ohto M, Okuda K. Portal hemodynamics in patients with gastric varices. A study in 230 patients with esophageal and/or gastric varices using portal vein catheterization. Gastroenterology 1988;95:434-440.

24. Ryan BM, Stockbrugger RW, Ryan JM. A pathophysiologic, gastroenterologic, and radiologic approach to the management of gastric varices. Gastroenterology 2004;126:1175-1189.

25. Maruyama H, Okugawa H, Yoshizumi H, Kobayashi S, Yokosuka O. Hemodynamic features of gastrorenal shunt: a Doppler study in cirrhotic patients with gastric fundal varices. Acad Radiol 2008;15:11481154.

26. Greenwald BD, Caldwell SH, Hespenheide EE, et al. N-2-butyl-cyanoacrylate for bleeding gastric varices: a United States pilot study and cost analysis. Am J Gastroenterol 2003;98:1982-1988.

27. Kim MY, Um SH, Baik SK, et al. Clinical features and outcomes of gastric variceal bleeding: retrospective Korean multicenter data. Clin Mol Hepatol 2013;19:36-44.

28. Seo YS. Prevention and management of gastroesophageal varices. Clin Mol Hepatol 2018;24:20-42.

29. Lim YS. Practical approach to endoscopic management for bleeding gastric varices. Korean J Radiol 2012;13 Suppl 1:S40-S44.
30. Cheng LF, Wang ZQ, Li CZ, Lin W, Yeo AE, Jin B. Low incidence of complications from endoscopic gastric variceal obturation with butyl cyanoacrylate. Clin Gastroenterol Hepatol 2010;8:760-766.

31. Kim JW, Baik SK, Kim KH, et al. [Effect of endoscopic sclerotherapy using N-butyl-2-cyanoacrylate in patients with gastric variceal bleeding]. Korean J Hepatol 2006;12:394-403.

32. Paik CN, Kim SW, Lee IS, et al. The therapeutic effect of cyanoacrylate on gastric variceal bleeding and factors related to clinical outcome. J Clin Gastroenterol 2008;42:916-922.

33. Jun $\mathrm{CH}$, Kim KR, Yoon JH, et al. Clinical outcomes of gastric variceal obliteration using N-butyl-2-cyanoacrylate in patients with acute gastric variceal hemorrhage. Korean J Intern Med 2014;29:437-444.

34. Qiao W, Ren Y, Bai Y, Liu S, Zhang Q, Zhi F. Cyanoacrylate injection versus band ligation in the endoscopic management of acute gastric variceal bleeding: meta-analysis of randomized, controlled studies based on the PRISMA statement. Medicine (Baltimore) 2015;94:e1725.

35. Park SW, Seo YS, Lee HA, et al. Changes in cardiac varices and their clinical significance after eradication of esophageal varices by band ligation. Can J Gastroenterol Hepatol 2016;2016:2198163.

36. Takeuchi M, Nakai Y, Syu A, Okamoto E, Fujimoto J. Endoscopic ligation of gastric varices. Lancet 1996;348:1038.

37. Toubia N, Sanyal AJ. Portal hypertension and variceal hemorrhage. Med Clin North Am 2008;92:551-574, viii.

38. Lo GH, Lin CW, Perng DS, et al. A retrospective comparative study of histoacryl injection and banding ligation in the treatment of acute type 1 gastric variceal hemorrhage. Scand J Gastroenterol 2013;48:1198-1204.

39. Tan PC, Hou MC, Lin HC, et al. A randomized trial of endoscopic treatment of acute gastric variceal hemorrhage: N-butyl-2-cyanoacrylate injection versus band ligation. Hepatology 2006;43:690-697.

40. El Amin H, Abdel Baky L, Sayed Z, et al. A randomized trial of endoscopic variceal ligation versus cyanoacrylate injection for treatment of bleeding junctional varices. Trop Gastroenterol 2010;31:279-284.

41. Mahadeva S, Bellamy MC, Kessel D, Davies MH, Millson CE. Cost-effectiveness of N-butyl-2-cyanoacrylate (histoacryl) glue injections versus transjugular intrahepatic portosystemic shunt in the management of acute gastric variceal bleeding. Am J Gastroenterol 2003;98:2688-2693.

42. Procaccini NJ, Al-Osaimi AM, Northup P, Argo C, Caldwell SH. Endoscopic cyanoacrylate versus transjugular intrahepatic portosystemic shunt for gastric variceal bleeding: a single-center U.S. analysis. Gastrointest Endosc 2009;70:881-887.

43. Chau TN, Patch D, Chan YW, Nagral A, Dick R, Burroughs AK. "Salvage" transjugular intrahepatic portosystemic shunts: gastric fundal compared with esophageal variceal bleeding. Gastroenterology 1998;114:981-987.

44. Barange K, Péron JM, Imani K, et al. Transjugular intrahepatic portosystemic shunt in the treatment of refractory bleeding from ruptured gastric varices. Hepatology 1999;30:1139-1143.

45. Sahagun G, Benner KG, Saxon R, et al. Outcome of 100 patients after transjugular intrahepatic portosystemic shunt for variceal hemorrhage. Am J Gastroenterol 1997;92:1444-1452.

46. Sanyal AJ, Freedman AM, Luketic VA, et al. Transjugular intrahepatic portosystemic shunts for patients with active variceal hemorrhage unresponsive to sclerotherapy. Gastroenterology 1996;111:138-146.

47. Imai Y, Nakazawa M, Ando S, Sugawara K, Mochida S. Long-term outcome of 154 patients receiving balloon-occluded retrograde transvenous obliteration for gastric fundal varices. J Gastroenterol Hepatol 2016;31:1844-1850

48. Jang SY, Kim GH, Park SY, et al. Clinical outcomes of balloon-occluded retrograde transvenous obliteration for the treatment of gastric variceal hemorrhage in Korean patients with liver cirrhosis: a retrospective multicenter study. Clin Mol Hepatol 2012;18:368-374.

49. Park JK, Saab S, Kee ST, et al. Balloon-occluded retrograde transvenous obliteration (BRTO) for treatment of gastric varices: review and meta-analysis. Dig Dis Sci 2015;60:1543-1553.

50. Wang YB, Zhang JY, Gong JP, Zhang F, Zhao Y. Balloon-occluded 
retrograde transvenous obliteration versus transjugular intrahepatic portosystemic shunt for treatment of gastric varices due to portal hypertension: a meta-analysis. J Gastroenterol Hepatol 2016;31:727-733.

51. Gwon DI, Kim YH, Ko GY, et al. Vascular plug-assisted retrograde transvenous obliteration for the treatment of gastric varices and hepatic encephalopathy: a prospective multicenter study. J Vasc Interv Radiol 2015;26:1589-1595.

52. Ibrahim M, El-Mikkawy A, Abdel Hamid M, et al. Early application of haemostatic powder added to standard management for oesophagogastric variceal bleeding: a randomised trial. Gut 2019;68:844-853.

53. Escorsell À, Pavel O, Cárdenas A, et al. Esophageal balloon tamponade versus esophageal stent in controlling acute refractory variceal bleeding: a multicenter randomized, controlled trial. Hepatology 2016;63:19571967.

54. Boustière C, Dumas O, Jouffre C, et al. Endoscopic ultrasonography classification of gastric varices in patients with cirrhosis. Comparison with endoscopic findings. J Hepatol 1993;19:268-272.

55. Bhatia V. Endoscopic ultrasound (EUS) for esophageal and gastric varices: how can it improve the outcomes and reduce complications of glue injection. J Clin Exp Hepatol 2012;2:70-74.

56. Bhat YM, Weilert F, Fredrick RT, et al. EUS-guided treatment of gastric fundal varices with combined injection of coils and cyanoacrylate glue: a large U.S. experience over 6 years (with video). Gastrointest Endosc 2016;83:1164-1172. 